\title{
Complications of laparoscopic rectal cancer surgery
}

\author{
Marta Climent, Sean T. Martin \\ Department of Colorectal Surgery and Centre for Colorectal Diseases, St. Vincent's University Hospital, Dublin 4, Ireland.
}

Correspondence to: Dr. Sean T. Martin, Department of Colorectal Surgery and Centre for Colorectal Diseases, St. Vincent's University Hospital, Elm Park, Dublin 4, Ireland. E-mail: drseanmartin@gmail.com

How to cite this article: Climent M, Martin ST. Complications of laparoscopic rectal cancer surgery. Mini-invasive Surg 2018;2:45. http://dx.doi.org/10.20517/2574-1225.2018.62

Received: 14 Sep 2018 First Decision: 19 Sep 2018 Revised: 26 Oct 2018 Accepted: 28 Nov 2018 Published: 28 Dec 2018

Science Editor: Gordon N. Buchanan Copy Editor: Cui Yu Production Editor: Huan-Liang Wu

\begin{abstract}
Laparoscopic rectal cancer surgery has widely been adopted over the past decade. With technical advances, data have shown equivalent outcomes with open surgery. In this paper, we discuss the potential complications of laparoscopic anterior resection, the need for early recognition and prompt management.
\end{abstract}

Keywords: Rectal cancer, postoperative complications, laparoscopic anterior resection

\section{INTRODUCTION}

Laparoscopic anterior resection (LAR) is currently a routine practice in specialized high-volume centres, with equivalent oncological outcomes in historical, open surgery ${ }^{[1-3]}$. Appropriate pelvic dissection can be measured by the adequacy of circumferential margin (CRM) and distal margin, both are risk factors of local recurrence. No difference in CRM positivity has been shown in patients undergoing open and LAR in the large, multicentre randomised controlled trials, such as the CLASSIC trial ${ }^{[1]}(14 \%$ vs. $16 \%$, respectively). LAR remains a technically challenging technique, particularly in the male pelvis, because of limited space in the pelvic cavity. It is estimated that a learning curve of 60-80 resections are required to obtain proficiency ${ }^{[4]}$. Data suggest that the learning curve is an important risk factor for postoperative complications ${ }^{[5]}$.

Similarly, many data exist to suggest that postoperative complications may promote tumour recurrence and decrease long-term survival ${ }^{[6,7]}$, although there is no general consensus among patients undergoing low anterior resection for rectal cancer ${ }^{[8]}$. Post-operative complications can be classified according to time-line related to surgery ${ }^{[1,8]}$, although most authors use well-known classification systems such as Clavien-Dindo ${ }^{[9]}$ [Table 1]. 
Table 1. Classification of post-operative complications according to Clavien-Dindo

\begin{tabular}{ll}
\hline Grade & \multicolumn{1}{c}{ Definition } \\
\hline I & Any deviation from the normal postoperative course without the need for pharmacological treatment or \\
II & surgical, endoscopic, and radiological interventions \\
III & Requiring pharmacological treatment with drugs other than such allowed for grade I complications \\
IIIa & Requiring surgical, endoscopic or radiological intervention \\
IIIb & Intervention not under general anaesthesia \\
IV & Intervention under general anaesthesia \\
IVa & Life-threatening complication, requiring IC/ICU management \\
IVb & Single organ dysfunction (including dialysis) \\
$\mathrm{V}$ & Multiorgan dysfunction \\
\hline
\end{tabular}

IC: intermediate care; ICU: intensive care unit

\section{EARLY POSTOPERATIVE COMPLICATIONS}

Morbidity rates occurred within 30 days of the LAR ranged from $25 \%-32 \%{ }^{[1,8]}$ while mortality during the same period reaches $6 \%$ to $8 \%{ }^{[5,8]}$.

\section{Surgical site infection}

Surgical site infection (SSI) includes incisional or wound infection and organ space infection occurring within 30 days after surgery.

\section{Incisional SSI}

Incisional SSI is further divided by the Centres for Disease Control and Prevention ${ }^{[10]}$ into superficial incisional SSI, involving only the skin and subcutaneous tissue, and those involving deeper soft tissues, known as deep incisional SSI. Wound infection is defined by the presence of purulent drainage from the superficial incision with organisms isolated on its culture and signs or symptoms suggestive of infection, such as erythema, induration and pain. Superficial SSI is one of the most common complications after anterior resection, being described in $6 \%-10 \%$ of $\operatorname{cases}^{[1,2]}$. A multivariate analysis showed that wound infection was related to tumour stage, a converted laparoscopic procedure and open surgery ${ }^{[11]}$. The use of $2 \%$ chlorhexidine gluconate in $70 \%$ isopropyl alcohol skin preparation before surgery may reduce the rate of SSI in clean-contaminated surgery compared to povidone-iodine, supported data from two systematic reviews and meta-analysis, albeit with limitations in data interpretation due to heterogeneity ${ }^{[12,13]}$.

\section{Organ space SSI}

Organ space SSI includes anastomotic leakage (AL) and any intra-abdominal or pelvic abscess diagnosed with radiological examination or reoperation, with the presence of purulent discharge from a drain, confirmed by laboratory culture. This broad definition makes its interpretation and comparison between series of patients difficult, with the uncertainty of whether a pelvic abscess occurs in the presence of, or absence of, anastomotic insufficiency ${ }^{[11]}$.

The rate of intra-abdominal or pelvic sepsis after rectal cancer resection varies between series, but is generally accepted to occur in between $12 \%-17 \%$ of patients ${ }^{[14,15]}$. In the presence of a localized abscess, a percutaneous computed tomography (CT)-guided drain placed in interventional radiology combined with intravenous antibiotics is the cornerstone of management. Transrectal or transperineal ultrasound-guided drainage may also be utilized for pelvic sepsis in the presence of a low anastomotic leak ${ }^{[16]}$. Where an abscess is not suitable for percutaneous drainage or there is an absence of radiological expertise, surgical lavage should be considered, which can be facilitated laparoscopically with good control of sepsis ${ }^{[8]}$.

\section{Anastomotic leak}

The most common postoperative complication after LAR is AL, with an incidence of $5.5 \%-8 \%$ with significant impact on morbidity and mortality ${ }^{[1,3]}$. There is a wide variability in the terminology used in 
Table 2. Risk factors associated with anastomotic leakage

\begin{tabular}{ll}
\hline Modifiable risk factors & Non-modifiable risk factors \\
\hline Smoking or previous smoking & Male gender \\
Obesity & Age $>60$ years \\
Alcohol (> 21 units per week) & Previous radiotherapy \\
Neoadjuvant radiotherapy & ASA grade score $>$ II \\
Immunosuppressant treatment & Comorbidities \\
Malnutrition & Diabetes mellitus \\
Preoperative weight loss $>10 \%$ & Renal disease \\
Hypoalbuminemia & COPD \\
& Vascular disease \\
& Emergency surgery \\
& Distal anastomosis \\
& Advanced neoplasia \\
\hline
\end{tabular}

ASA: American Society of Anaesthesiologists; COPD: chronic obstructive pulmonary disease

the literature, which makes comparison difficult, but it is widely agreed that an AL is a breach in a surgical anastomosis between two hollow viscera, with or without luminal content extravasation ${ }^{[17]}$. Male gender and low anastomosis are risk factors of AL after an anterior resection; probably because of narrower pelvis in the male, and suboptimal blood supply for distal anastomoses ${ }^{[17-19]}$. In a multivariate analysis performed with data from the Swedish rectal cancer registry, level of anastomosis $\leq 6 \mathrm{~cm}$. American Society of Anaesthesiologists grade $>2$, and severe bleeding were identified as risk factors of $\mathrm{AL}^{[19]}$. Other risk factors associated with AL are immunosuppression, obesity, current or previous heavy smoking and malnutrition $^{[17,18]}$ [Table 2]. Preoperative radiotherapy was previously postulated as being etiologic ${ }^{[18]}$, but larger randomised controlled trials, such as The Medical Research Council CR07 and National Cancer Institute of Canada Clinical Trials Group C016 showed no difference of AL between patients undergoing anterior resection with or without neoadjuvant radiotherapy with patients who had postoperative chemoradiotherapy ${ }^{[20]}$.

The use of preoperative mechanical bowel preparation, remains controversial, and a recent review of 1,369 patients who underwent elective rectal cancer resection demonstrated a significantly lower rate of clinical anastomotic leak in the group who had surgery without mechanical bowel preparation ${ }^{[21]}$. The value of a defunctioning stoma is still not clear. Some studies defend that a diverting stoma does not prevent AL, rather it facilitates management of the consequences of a leak; therefore, the use of a diverting stoma is a safe option in high-risk patients ${ }^{[19]}$. However, two meta-analyses ${ }^{[22,23]}$ reported a significant benefit of defunctioning stoma reducing the rate of $\mathrm{AL}$ and reoperations related to leakage, although the number of randomized control trials included in both studies was small. It has been suggested that the use of pelvic drainage after anterior resection may detect early $\mathrm{AL}$, reducing the incidence of pelvic sepsis and decreasing the need of reoperation. However, some studies have reported potential risks related to the use of pelvic drains such as bowel perforation, vessel injury, infection around the site of its entrance, and pain ${ }^{[15]}$. Recently, a prospective randomized trial showed no benefit in reduction of pelvic sepsis or in the time to diagnosis the AL among patients with suction pelvic drain after rectal excision for cancer ${ }^{[24]}$. Some groups support the use of laser fluorescence angiography intraoperatively in order to evaluate perfusion of the proximal colon prior to creation of the anastomosis ${ }^{[25]}$, but level 1 evidence is required before this becomes universally accepted as a standard practice. There is consensus that a surgical anastomosis should be tension-free with good blood supply, often necessitating splenic flexure mobilisation and inferior mesenteric vein ligation under the inferior border of the pancreas ${ }^{[18]}$.

Early diagnosis of AL is critical to managing the ensuing pelvic sepsis and treating high-risk patients ${ }^{[17]}$. Classically, an anastomotic leak is diagnosed between postoperative day 6 to 9, although the range is wide $^{[26]}$. An abnormal abdominal examination, in addition to increased systemic inflammatory response 


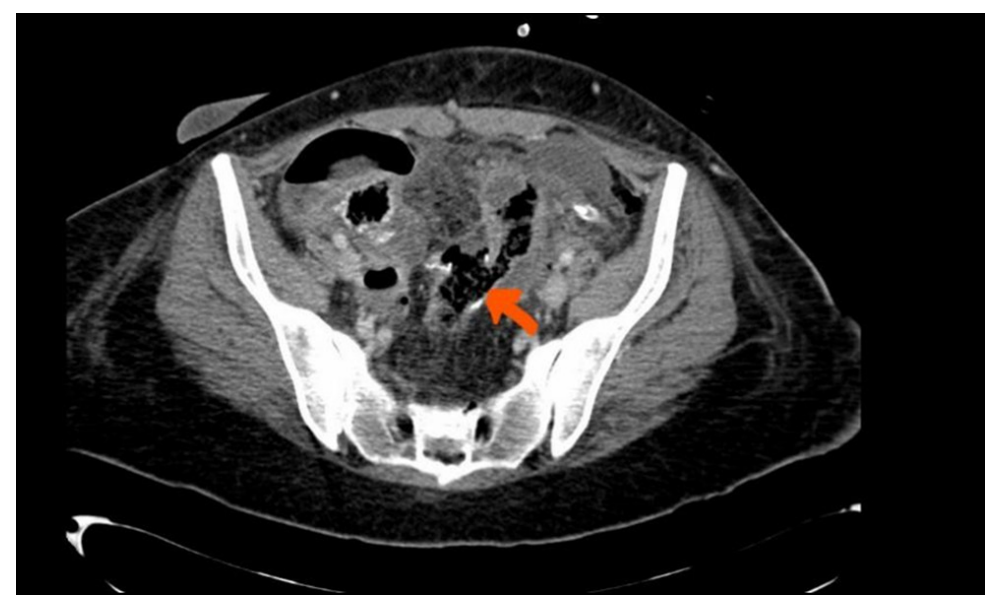

Figure 1. Anterior defect on end-to-end stapled anastomosis with a faecal collection

syndrome after an anterior resection should prompt a high index of suspicion of an AL, but some leaks can present with a more insidious course and become evident later, presenting as a pelvic abscess or with the presence of faeces in the pelvis ${ }^{[16]}$ [Figure 1]. In order to detect AL promptly, some earlier indicators are used. A systematic review and meta-analysis performed with 2483 patients following colorectal surgery showed that serum C-reactive protein concentration measured on day 3-5 after resection is a useful negative predictive test but not a good positive predictor of $\mathrm{AL}$, although included studies did not distinguish between colonic and rectal resection ${ }^{[26]}$. In patients who are not systemically unwell or unstable, a CT with water-soluble contrast enema may confirm the clinical suspicion of AL, with a sensitivity of 0.91, but the appearance of an intact staple line does not rule out an AL, with high false-negative rates reported in the literature ${ }^{[27]}$. This may be related to the fact that post-operative CT may be performed before there is radiological evidence of $\mathrm{AL}^{[17]}$.

A disrupted colorectal anastomosis can be salvaged in the majority of cases often utilising minimally invasive techniques; however, in a haemodynamically unstable patient an emergent laparotomy is mandatory ${ }^{[8]}$. Laparoscopy enables the surgeon to assess the peritoneal cavity and the status of the anastomosis ${ }^{[16,28]}$ with faster recovery in selected patients ${ }^{[29]}$. However, there is no clear evidence of superiority to open surgery ${ }^{[30]}$. Among the methods used to manage AL, diverting stoma with peritoneal lavage with or without intraabdominal drain placement was the most common method of managing $\mathrm{AL}^{[30]}$. Small leaks $(<30 \%$ of the circumference) could be treated with primary repair of the anastomosis with a defunctioning stoma, while in case of severe peritoneal contamination with large AL or colonic ischaemia, a Hartmann's procedure is recommended $^{[8]}$. A transanal approach with anoscopy is an option in order to perform a primary repair on a low anastomosis ( $<5 \mathrm{~cm}$ from the anal verge) while a transanal endoscopic approach is recommended for higher anastomosis (anastomosis $\geq 5 \mathrm{~cm}$ from anal verge) ${ }^{[28]}$. The transrectal ultrasound-guided drainage performed by interventional radiologists has good results, as mentioned in "Organ space SSI" ${ }^{\text {"[16] }}$ and in case of sinus persistence, the use of an endo-sponge is a good alternative, avoiding protecting stoma in some scenarios. This device is inserted transanally, after washing the cavity, and attached to a low vacuum wound drainage system enhancing granulating tissue and cavity closure ${ }^{[31]}$.

\section{Haemorrhage}

Intraoperative bleeding is the most common intraoperative complication ${ }^{[1]}$, and may be difficult to manage with fatality imminent if not rapidly controlled. Pelvic haemorrhage can occur with injury of the presacral venous plexus (PSVP) and the sacral basivertebral veins if dissection is posterior to the mesorectal plane, behind the pre-sacral fascia, occurring in $4.6 \%$ to $9.4 \%$ of cases $^{[32]}$. PSVP is formed by the two lateral sacral veins and the middle sacral vein, anastomosing with the internal vertebral system through the basivertebral vessels emerging from the sacral foramina. It is localised underneath the presacral fascia, being easily 
lacerated, with high propensity to bleed ${ }^{[33]}$. Managing bleeding from the pre-sacral veins is challenging; conventional methods such as direct sutures often fail and may exacerbate bleeding. It is often necessary to pack the pelvis with large swabs, the direct pressure arresting haemorrhage. A "second-look laparotomy" is required in 24-48 $\mathrm{h}$ to remove the packs, as leaving a large volume of foreign body in situ can increase the risk of pelvic sepsis ${ }^{[34]}$. Sterile thumbtacks could be used as an alternative, but they are ineffective in case of diffuse haemorrhage, and some authors report chronic pain and anastomotic fistulas related to their placement in the presacral space ${ }^{[33]}$. Other techniques have been suggested such as topical haemostatic $\operatorname{agents}^{[32]}$, direct or indirect coagulation with spray electrocautery, argon or bipolar coagulation. Suture ligation of the presacral veins in circles with 4-0 silk suture thread is an alternative with good control of bleeding if other techniques fail ${ }^{[34]}$.

Iatrogenic splenic injury is described in $2 \%$ of left-sided colonic resections, caused by inadvertent traction or capsular tear due to adhesions during splenic flexure mobilization ${ }^{[35]}$. Splenectomy is typically a last resort, with spleen conserving manoeuvres such as splenorrhapy or application of topical haemostatic agents preferable, as splenectomy has life-long implications for patients such as overwhelming post-splenectomy infection (OPSI). In order to prevent OPSI, the polyvalent pneumococcal vaccine, Haemophilus influenzae type $\mathrm{b}$ conjugate vaccine and the meningococcal polysaccharide vaccine are administered within 2 weeks of splenectomy. The use of antibiotics might reduce but not abolish OPSI, although it's use is based on limited evidence ${ }^{[36]}$.

Limited haematochezia with the first bowel movement is not unusual after surgery, described in 6.5\% of cases ${ }^{[37]}$, but severe bleeding can be quite challenging because of the risk of compromising a healing anastomosis. Treatment should initially involve prompt resuscitation, including blood transfusion depending on patient's clinical status, age and comorbidities. If bleeding per rectum does not stop spontaneously, endoscopic assessment of anastomosis is undertaken, with copious lavage reported as being successful in securing haemostasis, reserving surgical intervention when there is failure to arrest bleeding or haemodynamic instability ${ }^{[37,38]}$. When dealing with low anastomoses, an examination under anaesthesia with transanal suture placement or rectal packing is effective. If these measures fail, one is committed to taking down the anastomosis.

\section{Urinary injury}

Urinary injury, namely to the bladder or ureter, occurs in $2 \%-2.8 \%$ of $\operatorname{LAR}^{[1,39]}$. Ureteric injury may occur during the mobilisation of sigmoid colon, when elevating the mesocolon off the retroperitoneum or along the lateral pelvic sidewall, on entry into the pelvis ${ }^{[39]}$. Ureteral injury may be diagnosed intraoperatively, but unfortunately, $50 \%-70 \%{ }^{[40]}$ of cases the diagnosis is made post-operatively with a high volume of serous fluid in the pelvic drain with low urinary output or localised peritonitis. To confirm ureter disruption, a cystoscopy and a retrograde pyelogram can be performed, ideally following a CT-Urogram ${ }^{[40]}$.

If diagnosed intra-operatively, the ureter may be repaired primarily with an end-to-end anastomosis over a JJ-ureteral stent with absorbable sutures; some authors reporting this successful approach laparoscopically ${ }^{[8]}$. When a long defect is discovered, or the ureter has been transacted using an energy device, management is dictated by the location of the defect, techniques such as the ureteroneocystostomy with or without vesico-psoas hitch or a Boari tubularized flap may be required ${ }^{[40]}$.

Bladder injury is commonly associated with electrocoagulation tears during the dissection of the rectum anterior wall. Intermittent suturing with absorbable sutures and leaving of urethral catheter in situ for 7-10 days is necessary ${ }^{[40]}$. A post-operative cystogram is mandatory prior to removing the urinary catheter. Where there is suspicion of urinary tract injury administration of intravenous indigo-carmine or methylene blue, which are excreted in the urine, may be beneficial in identifying a defect ${ }^{[41]}$. 


\section{Postoperative ileus. Intestinal obstruction}

Postoperative ileus (POI) is defined as a transient cessation of coordinated bowel motility after surgical intervention, which prevents the effective transit of intestinal contents or tolerance of oral intake ${ }^{[42]}$. POI can be secondary of an intra-abdominal complications such as an abscess or AL, but may occur ab-initio, in the context of surgical stress response, which stimulates inhibitory reflexes and releases inflammatory mediators resulting in impaired bowel motility ${ }^{[43]}$.

Some authors have suggested that laparoscopic surgery is associated with less frequent POI compared to open surgery due to the minimal intestinal manipulation leading to decreased local inflammatory response ${ }^{[3,5]}$. However, there is a dearth of evidence and no accepted consensus that laparoscopic surgery in major colorectal surgery is protective against $\mathrm{POI}^{[1]}$. To date, no good pharmacological treatment is available to diminish POI but chewing sugarless gum after surgery ${ }^{[43]}$ and early introduction of enteral nutrition after rectal surgery have been associated with a significant reduction in the time to return of bowel function ${ }^{[44]}$.

Kim et al. ${ }^{[45]}$ defined early postoperative small bowel obstruction (SBO), which differs from the POI in that it occurs secondary to early adhesions, lasting less than 7 days and usually resolved conservatively. In a systematic review of postoperative complications after colorectal surgery, early postoperative SBO was the second commonest cause of reoperation, which can be managed with a laparoscopic approach ${ }^{[30]}$. Often, the cause of intestinal obstruction is adhesions or an internal hernia ${ }^{[8]}$.

\section{Cardio-respiratory complications and other conditions}

Cardiopulmonary dysfunction has been described in $4 \%$ of patients who underwent anterior resection. Chest infection incidence after LAR is $3.4 \%-10 \%{ }^{[1,18]}$, being slightly higher after LAR in comparison to open surgery due to greater operating time. Incidence of deep venous thrombosis has decreased considerably, with universal adoption of pneumatic calf compression devices, and the use of low molecular weight heparin extended up to 30 days postoperatively according to the European Society of Medical Oncology ${ }^{[46]}$. Another minor early complication associated with anterior resection is urinary retention, requiring temporary catheterization, following failed trial of voiding.

\section{LONG-TERM COMPLICATIONS}

Long-term morbidities are those that take place between the 30th post-operative day to 3 years following $\operatorname{LAR}^{[47]}$.

\section{Low anterior resection syndrome}

Sphincter-preserving procedures with a low colorectal or coloanal anastomosis are associated with bowel dysfunction, which negatively affects the patient's quality of life (QOL). It may be multifactorial, including diminished rectal compliance, autonomic neuropraxia or neuropathy and impairment of internal anal sphincter tone ${ }^{[48]}$. Low anterior resection syndrome (LARS) is defined by high frequency of bowel movements, clustering, incomplete evacuation, diarrhoea, incontinence for flatus and stool, urgency, and bowel movements at night ${ }^{[49]}$. The severity of LARS can be measured with LARS score, a fiveitem instrument giving a score from 0 to 42 . A range from 30 to 42 on the LARS questionnaire indicates major LARS, from 21 to 29 minor LARS, whereas scores below 21 can rule out LARS ${ }^{[50]}$. Unfortunately, its incidence is underestimated and its impact under-appreciated, as a recent survey among colorectal surgeons of different countries shows ${ }^{[51]}$. LARS is present in $55.2 \%-58 \%$ of patients who undergo low $\mathrm{LAR}^{[4,52]}$, being more frequent after a low anastomosis and in young patients who received neoadjuvant chemoradiotherapy $^{[52]}$.

Management of LARS is quite challenging because of a dearth of successful treatment options. Conservative management consists of dietary adjustment adhering to a low fibre diet, antidiarrheal 
treatment, pelvic floor rehabilitation, biofeedback and colonic irrigation ${ }^{[49,51]}$. Some authors have suggested the use of sacral nerve stimulation after the failure of conservative management, with a success rate of $75 \%$ after a median follow up of 18 months, but its use has been described only in a small series of patients ${ }^{[49,53]}$. Further prospective studies are required to assess the success of this technique.

\section{Incisional and port-side hernia}

Laparoscopic approaches have reduced the incidence of incisional hernia, in $2.3 \%^{[54]}$ to $13 \%{ }^{[2]}$ depending on the length of follow-up, but many rectal resections still require an abdominal incision for specimen extraction. A multivariate analysis performed by DeSouza et al ${ }^{[55]}$ identified high body-mass index, wound infection and diabetes as risk factors for incisional hernia, and the Pfannenstiel incision as independent protector of an incisional hernia. Many surgeons now choose to avoid a midline extraction site to minimize this complication. In a review of patients undergoing laparoscopic colorectal surgery, midline incisional hernia accounted for $84 \%$ of all hernias compared to $4.8 \%$ for Pfannenstiel incision ${ }^{[54]}$. However, authors report no benefit in extending the left iliac fossa port (transverse incision) rather than a midline incision, with similar incidence of extraction site incisional hernia and wound infection rate ${ }^{[56]}$. In order to avoid the risk of incisional hernias, some authors suggest the use of prophylactic mesh. A randomized controlled trial with patients undergoing colorectal surgery through a midline incision shows a reduction of incisional hernia in the group with a prophylactic overlay large-pore polypropylene mesh by $20.2 \%$, without increase of SSIs with no mesh rejection ${ }^{[57]}$.

\section{Rectovaginal and colovesical fistulas}

Rectovaginal fistula (RVF) is thought to be an infrequent complication after LAR, approximately 3\%, appearing as a late complication, sometimes more than 3 months after surgery ${ }^{[58]}$. Clinical suspicion is confirmed by rectal and gynaecological examination, and by endoscopic and radiological investigations. Traditionally, previous hysterectomy and the experience of a surgeon using the circular stapler were described as prognostic factors of a RVF. Careful dissection between the rectal stump and posterior vaginal wall is required and a marked posterior angle introducing the circular stapler in the rectal stump, in order to avoid the inclusion of vaginal wall in the tissue rings (doughnuts) ${ }^{[59]}$. Other authors suggest malnutrition, neoadjuvant chemotherapy, tumour size $\geq 50 \mathrm{~mm}$, intraoperative bleeding and lateral lymph node dissection as risk factors for developing $\mathrm{RVF}^{[58]}$. The American Society of Colon and Rectal Surgeons recommends delaying surgical intervention for a period of 3 to 6 months to allow possible spontaneous healing of the fistula; in the event of acute inflammation, a draining seton may be required ${ }^{[60]}$. There is no consensus regarding the need for faecal diversion but in some cases, diversion alone may result in healing ${ }^{[60,61]}$. RVF after anterior resection are typically too high to be repaired with a perineal approach and often requires an abdominal approach, to redo the anastomosis with omentoplasty interposed between the vagina and the rectum. In refractories RVF, a proctectomy with colon pull-through provides good results, with the caveat that functional outcome is suboptimal ${ }^{[61]}$.

Some authors suggest that the persistence of an $\mathrm{AL}$, even when there is a discrete sinus (1\%-5\% of LAR) could be associated to a rectovaginal/rectourethral/colovesical fistula, or also to some degree of stenosis, recommending early repair of AL in order to avoid these complications ${ }^{[28]}$. Urinary sepsis and the presence of gas in the bladder in absence of catheterisation raise suspicion of colovesical fistula [Figure 2].

\section{Urinary and sexual dysfunction}

Autonomic nerves can be damaged during total mesorectal excision. Dissection along the avascular plane between presacral fascia and mesorectal fascia, the so called "holy plane", preserves sacral vessels and autonomic nerves including the superior hypogastric plexus, the hypogastric nerves, the pelvic (inferior hypogastric) plexus, the pelvic splanchnic nerves, and the neurovascular bundle of Walsh ${ }^{[52]}$. However, the presence of urinary and sexual dysfunction among patients who underwent an anterior resection, as 


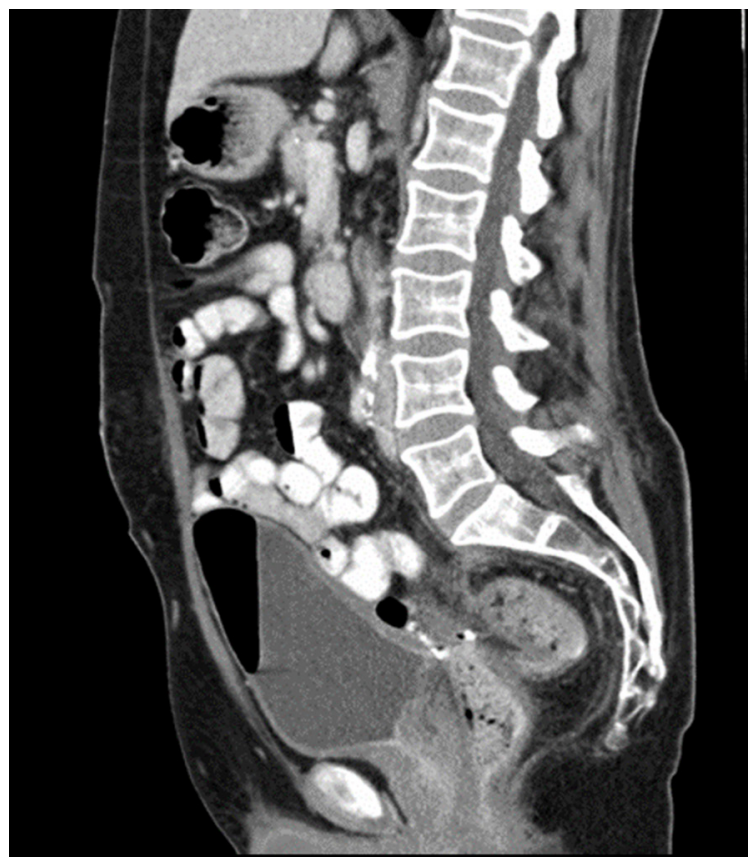

Figure 2. Colovesical fistula in a patient undergoing laparoscopic anterior resection. Air in the bladder in the absence of catheterisation

a result of thermal and/or ischemic injury, tension or local inflammatory damage of autonomic nerves is well recognised ${ }^{[62]}$. Special attention must be paid during dissection at the origin of the inferior mesenteric artery, during the posterior mobilization of the rectum and lateral and anterior dissection of the rectum to minimise risk of nerve injury ${ }^{[63]}$.

Due to sympathetic and parasympathetic nerve damage, patients describe incomplete urination, frequency of urination, interrupted urination, incontinence and low-flow urination. Urinary dysfunction may be easily evaluated with the International Prostate Symptom Score, which includes assessment of urinary symptoms and patient's QOL. Utilizing this scoring system, data suggest $12.7 \%$ of patients suffer from severe dysfunction after rectal resection ${ }^{[62]}$.

For appropriate diagnosis and follow-up of urogenital dysfunction, The International Index of Erectile Function form for men and the International Index of Female Sexual Function for women are valuable and validated instruments to assess sexual dysfunction ${ }^{[63]}$. Some studies have reported impotence in $20 \%-46 \%$ and ejaculatory disorders in $20 \%-60 \%$ of men, whereas in women symptoms include loss of libido, vaginal moisture loss, orgasm loss and dyspareunia, being reported by $30 \%$ to $65 \%$ of patients after $\operatorname{LAR}^{[62,63]}$. Damage of superior hypogastric plexus and hypogastric nerves causes bladder instability (loss of relaxation) and retrograde ejaculation or loss of ejaculation in men, whereas damage of inferior hypogastric plexus leads to difficulties in bladder emptying and impotence ${ }^{[63]}$.

\section{Stoma complications}

Stoma complications could be associated with significant morbidity, which is highest in the first 5 years postoperatively ${ }^{[64]}$. Some complications appear early in the postoperative course, such as fluid and electrolyte imbalance, peristomal dermatitis or stoma retraction because the bowel is under tension, often requiring stoma refashioning.

\section{Parastomal hernias}

There is a wide range of incidence of parastomal hernia, depending on the follow-up and the type of stoma. An incidence of $6.2 \%$ has been described for loop ileostomies, while the incidence is higher for colostomies 
depending on whether a hernia is diagnosed clinically $(48.1 \%)$ or radiologically $(80 \%)^{[65]}$. The fact that many ileostomies are temporary may lead to less incidence of long-term herniation ${ }^{[65]}$. Risk factors for the development of parastomal hernia are obesity, raised intra-abdominal pressure (chronic constipation, ascites, chronic cough), corticosteroid use, increased age, wound sepsis ${ }^{[6-69]}$, malnutrition, smoking ${ }^{[69]}$, diameter of the trephine and its location and emergency surgery without preoperative assessment by a stoma therapist ${ }^{[66]}$.

Current treatment options include non-operative management, if the parastomal hernia is asymptomatic or stoma relocation and repair of the fascial defect with or without mesh. Primary fascial repair has been associated with high recurrence, from $50 \%$ to $75 \%{ }^{[6,69]}$. Despite the fact that fewer recurrences are described with stoma relocation on the other side of the abdomen wall, there is a significant risk of an incisional hernia at the site of the original stoma and in addition, this technique could be limited if there are multiple previous surgeries ${ }^{[65]}$. The repair of fascial defect with mesh has been widely described with different techniques, placing the mesh on the top of the fascia of the rectus sheath (onlay), between the rectus abdominis muscle and posterior rectus sheath (sublay), and intraabdominal (underlay), fixed on to the peritoneum, which could be by open or laparoscopic approach. The onlay technique consists in the insertion of a polypropylene ring mesh around the stoma, avoiding a laparotomy, which may be convenient in high-risk patients. However, there is a high risk of recurrence and the infection rate is quite significant, $12.5{ }^{[66]}$, requiring the removal of the mesh. The sublay mesh technique and the underlay mesh technique have been associated with less recurrence compared to the onlay technique, likely because the mesh is placed on the high-pressure side of the abdominal wall ${ }^{[69]}$. Unfortunately, there are minimal long-term data on the effectiveness of sublay mesh technique. The two most popular underlay techniques are the slit mesh Keyhole technique and the Sugarbaker technique. Both involve hernia sac reduction, adhesiolysis, and appropriate mesh fixation. The Sugarbaker approach involves the bowel being exteriorized through the side of the mesh creating a tunnel between the abdominal wall and the prosthesis, in the Keyhole approach the bowel is inserted through a hole placed in the centre of the mesh. The Sugarbaker technique was modified from the original version to prevent recurrent hernias, and an overlap of 3-5 $\mathrm{cm}$ between the mesh and the adjacent fascia around the trephine opening is now mandatory ${ }^{[70]}$. The largest Sugarbaker and Keyhole cohorts are published by Hansson et al. ${ }^{[71]}$ in two different studies describing a recurrence of $37 \%$ after the Keyhole technique ${ }^{[71]}$ compared to a recurrence rate of $6.6 \%$ in the group of Sugarbaker technique ${ }^{[70]}$. Authors justify these results because the mesh material used, polytetrafluoroethylene (ePTFE), has a tendency to shrink, which widens the slit in the mesh and consequently results in a hernia recurrence. DeAsis et al. ${ }^{[68]}$ found also better results for the Sugarbaker technique but with a not insignificant risk of recurrence of $10.2 \%$. Expanded ePTFE meshes are the most common prostheses described in the literature to deal with laparoscopic intraperitoneal hernia repair because there is less risk of adhesions to the bowel ${ }^{[6,70]}$ compared to polypropylene mesh. However, the hydrophobicity of ePTFE and the lack of ingrowth of fibrocollagenous tissue into the prosthesis make it vulnerable to infection, so it is mandatory to avoid the use of mesh in a contaminated field ${ }^{[7]}$. Some authors have suggested the use of hybrid mesh types, with an inert mesh material such as polyvinylidene fluoride with a small amount of polypropylene on the parietal side, inducing ingrowth and incorporation ${ }^{[72]}$.

In order to prevent a parastomal hernia, some groups have suggested the use of mesh placed prophylactically in the sublay position at the time of stoma creation ${ }^{[73]}$. A recent metanalysis of 10 randomized trials, analysing 649 patients in total, found that mesh reduced the rate of parastomal hernia repair by $65 \%$, with a low rate of infection ${ }^{[7]}$. Nevertheless, the use of prophylactic mesh is still controversial and there is no clear consensus regarding it's use ${ }^{[66]}$.

\section{Other stoma complications}

Stoma prolapse is defined as bowel intussusception, which protrudes through the stomal orifice [Figure 3]. Traditionally it has been described the use of sugar for helping in the manual reduction because it benefits 


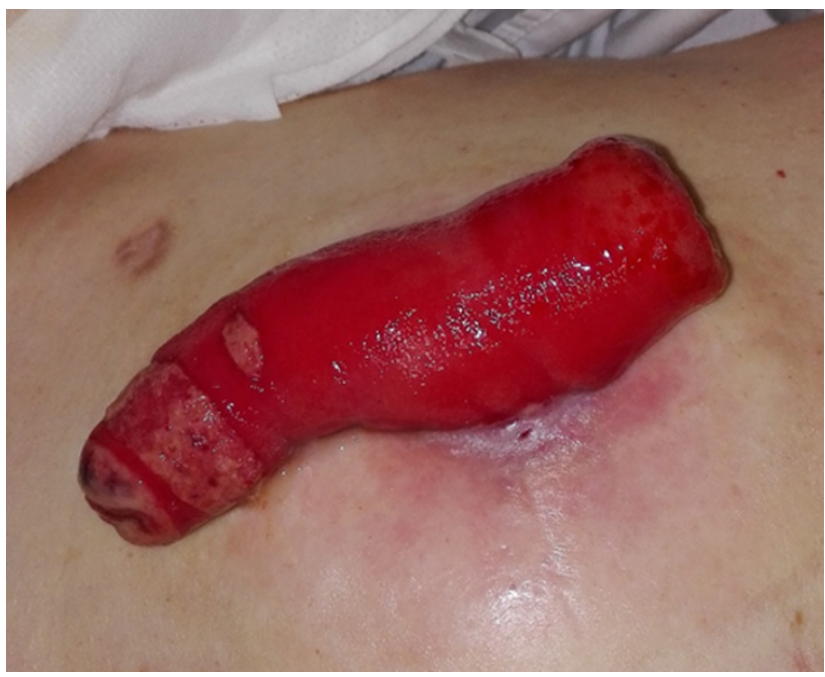

Figure 3. Prolapsed stoma

the exchange of fluids related to the osmotic gradient ${ }^{[64]}$. If there is any evidence of ischaemia, stoma should be refashioned.

Stomal stenosis is reported in $2 \%-15 \%$ of the stomas, and the commonest symptom is a noisy stoma when flatus is passed ${ }^{[64]}$. Management of this complication includes dilatations with Hagar's dilators and when it is not possible, surgical review of the stoma is recommended. Retraction of the stoma due to insufficient length of bowel, may be managed using convex appliance ${ }^{[75]}$.

\section{CONCLUSION}

Laparoscopic rectal cancer surgery is safe, in the hands of fellowship-trained specialist surgeons. Morbidity and mortality can be minimised by the early recognition of complications and involvement of the multidisciplinary team in management of such complications. Minimally invasive approaches are favoured by patients, and increasingly by surgeons, but the incidence and gravity of complications after laparoscopic rectal cancer surgery remain equivalent to traditional open surgery.

\section{DECLARATIONS}

\section{Authors' contributions}

Design, literature research, data analysis, manuscript writing, manuscript editing, manuscript revision: Climent M, Martin ST

\section{Availability of data and materials}

Not applicable.

\section{Financial support and sponsorship}

None.

\section{Conflicts of interest}

All authors declared that there are no conflicts of interest.

\section{Ethical approval and consent to participate}

Not applicable. 


\section{Consent for publication}

Not applicable.

\section{Copyright}

(c) The Author(s) 2018.

\section{REFERENCES}

1. Guillou PJ, Quirke P, Thorpe H, Walker J, Jayne DG, et al. Short-term endpoints of conventional versus laparoscopic-assisted surgery in patients with colorectal cancer (MRC CLASICC trial): multicentre, randomised controlled trial. Lancet 2005;365:1718-26.

2. Laurent C, Leblanc F, Bretagnol F, Capdepont M, Rullier E. Long-term wound advantages of the laparoscopic approach in rectal cancer. Br J Surg 2008;95:903-8.

3. Asoglu O, Balik E, Kunduz E, Yamaner S, Akyuz A, et al. Laparoscopic surgery for rectal cancer: outcomes in 513 patients. World J Surg 2013;37:883-92.

4. Son GM, Kim JG, Lee JC, Suh YJ, Cho HM, et al. Multidimensional analysis of the learning curve for laparoscopic rectal cancer surgery. J Laparoendosc Adv Surg Tech A 2010;20:609-17.

5. Shearer R, Gale M, Aly OE, Aly EH. Have early postoperative complications from laparoscopic rectal cancer surgery improved over the past 20 years? Color Dis 2013;15:1211-26.

6. Mirnezami A, Mirnezami R, Chandrakumaran K, Sasapu K, Sagar P, et al. Increased local recurrence and reduced survival from colorectal cancer following anastomotic leak: systematic review and meta-analysis. Ann Surg 2011;253:890-9.

7. Park EJ, Baik SH, Kang J, Hur H, Min BS, et al. The impact of postoperative complications on long-term oncologic outcomes after laparoscopic low anterior resection for rectal cancer. Medicine (Baltimore) 2016;95:e3271.

8. Cuccurullo D, Pirozzi F, Sciuto A, Bracale U, La Barbera C, et al. Relaparoscopy for management of postoperative complications following colorectal surgery: ten years experience in a single center. Surg Endosc 2015;29:1795-803.

9. Dindo D, Demartines N, Clavien PA. Classification of surgical complications; a new proposal with evaluation in a cohort of 6336 patients and results of a survey. Ann Surg 2004;240:205-13.

10. Bruce J, Russell EM, Mollison J, Krukowski ZH. The measurement and monitoring of surgical adverse events. Health Technol Assess 2001;5:1-194.

11. Biondo S, Kreisler E, Fraccalvieri D, Basany EE, Codina-Cazador A, et al. Risk factors for surgical site infection after elective resection for rectal cancer. A multivariate analysis on 2131 patients. Color Dis 2012;14:e95-102.

12. Noorani A, Rabey N, Walsh SR, Davies RJ. Systematic review and meta-analysis of preoperative antisepsis with chlorhexidine versus povidone-iodine in clean-contaminated surgery. Br J Surg 2010;97:1614-20.

13. Privitera GP, Costa AL, Brusaferro S, Chirletti P, Crosasso P, et al. Skin antisepsis with chlorhexidine versus iodine for the prevention of surgical site infection: a systematic review and meta-analysis. Am J Infect Control 2017;45:180-9.

14. Paun BC, Cassie S, MacLean AR, Dixon E, Buie WD. Postoperative complications following surgery for rectal cancer. Ann Surg 2010;251:807-18

15. Denost Q, Rouanet P, Faucheron JL, Panis Y, Meunier B, et al. To drain or not to drain infraperitoneal anastomosis after rectal excision for cancer: the GRECCAR 5 randomized trial. Ann Surg 2017;265:474-80.

16. Pera M, Delgado S, García-Valdecasas JC, Pera M, Castells A, et al. The management of leaking rectal anastomoses by minimally invasive techniques. Surg Endosc 2002;16:603-6.

17. McDermott FD, Heeney A, Kelly ME, Steele RJ, Carlson GL, et al. Systematic review of preoperative, intraoperative and postoperative risk factors for colorectal anastomotic leaks. Br J Surg 2015;102:462-79.

18. Dulucq JL, Wintringer P, Stabilini C, Mahajna A. Laparoscopic rectal resection with anal sphincter preservation for rectal cancer: longterm outcome. Surg Endosc 2005;19:1468-74.

19. Jestin P, Påhlman L, Gunnarsson U. Risk factors for anastomotic leakage after rectal cancer surgery: a case-control study. Colorectal Dis 2008;10:715-21.

20. Sebag-Montefiore D, Stephens RJ, Steele R, Monson J, Grieve R, et al. Preoperative radiotherapy versus selective postoperative chemoradiotherapy in patients with rectal cancer (MRC CR07 and NCIC-CTG C016): a multicentre, randomised trial. Lancet 2009;373:811-20.

21. Ji WB, Hahn KY, Kwak JM, Kang DW, Baek SJ, et al. Mechanical bowel preparation does not affect clinical severity of anastomotic leakage in rectal cancer surgery. World J Surg 2016;41:1366-74.

22. Hüser N, Michalski CW, Erkan M, Schuster T, Rosenberg R, et al. Systematic review and meta-analysis of the role of defunctioning stoma in low rectal cancer surgery. Ann Surg 2008;248:52-60.

23. Wu SW, Ma CC, Yang Y. Role of protective stoma in low anterior resection for rectal cancer: a meta-analysis. World J Gastroenterol 2014:21:18031-7.

24. Karliczek A, Jesus EC, Matos D, Castro AA, Atallah AN, et al. Drainage or nondrainage in elective colorectal anastomosis: a systematic review and meta-analysis. Color Dis 2006;8:259-65.

25. Kudszus S, Roesel C, Schachtrupp A, Höer JJ. Intraoperative laser fluorescence angiography in colorectal surgery: a noninvasive analysis to reduce the rate of anastomotic leakage. Langenbecks Arch Surg 2010;395:1025-30.

26. Singh PP, Zeng IS, Srinivasa S, Lemanu DP, Connolly AB, et al. Systematic review and meta-analysis of use of serum C-reactive protein levels to predict anastomotic leak after colorectal surgery. Br J Surg 2014;101:339-46.

27. Kaur P, Karandikar SS, Roy-Choudhury S. Accuracy of multidetector CT in detecting anastomotic leaks following stapled left-sided 
colonic anastomosis. Clin Radiol 2014;69:59-62.

28. Chen WT, Bansal S, Ke TW, Chang SC, Huang YC, et al. Combined repeat laparoscopy and transanal endolumenal repair (hybrid approach) in the early management of postoperative colorectal anastomotic leaks: technique and outcomes. Surg Endosc 2018;32:4472-80.

29. Vennix S, Bakker OJ, Prins HA, Lips DJ. Re-interventions following laparoscopic surgery for colorectal cancer: data from 818 individuals from the Dutch surgical colorectal audit. J Laparoendosc Adv Surg Tech A 2014;24:751-6.

30. Wright DB, Koh CE, Solomon MJ. Systematic review of the feasibility of laparoscopic reoperation for early postoperative complications following colorectal surgery. Br J Surg 2017;104:337-46.

31. Riss S, Stift A, Meier M, Haiden E, Grünberger T, et al. Endo-sponge assisted treatment of anastomotic leakage following colorectal surgery. Colorectal Dis 2010;12:e104-8.

32. Bonello VA, Bhangu A, Fitzgerald JE, Rasheed S, Tekkis P. Intraoperative bleeding and haemostasis during pelvic surgery for locally advanced or recurrent rectal cancer: a prospective evaluation. Tech Coloproctol 2014;18:887-93.

33. Celentano V, Ausobsky JR, Vowden P. Surgical management of presacral bleeding. Ann R Coll Surg Engl 2014;96:261-5.

34. Jiang J, Li X, Wang Y, Qu H, Jin Z, et al. Circular suture ligation of presacral venous plexus to control presacral venous bleeding during rectal mobilization. J Gastrointest Surg 2013;17:416-20.

35. McGory ML, Zingmond DS, Sekeris E, Ko CY. The Significance of Inadvertent Splenectomy During Colorectal Cancer Resection. Arch Surg 2007;142:668-74.

36. Di Sabatino A, Carsetti R, Corazza GR. Post-splenectomy and hyposplenic states. Lancet 2011;378:86-97.

37. Ma JJ, Ling TL, Lu AG, Zong YP, Feng B, et al. Endoscopic management for the assessment and treatment of anastomotic bleeding in laparoscopic anterior resection for rectal cancer. Surg Laparosc Endosc Percutan Tech 2014;24:465-9.

38. Martínez-Serrano MA, Parés D, Pera M, Pascual M, Courtier R, et al. Management of lower gastrointestinal bleeding after colorectal resection and stapled anastomosis. Tech Coloproctol 2009;13:49-53.

39. Zhu QL, Feng B, Lu AG, Wang ML, Hu WG, et al. Laparoscopic low anterior resection for rectal carcinoma: complications and management in 132 consecutive patients. World J Gastroenterol 2010;16:4605-10.

40. Burks FN, Santucci RA. Management of iatrogenic ureteral injury. Ther Adv Urol 2014;6:115-24.

41. Gomez RG, Ceballos L, Coburn M, Corriere JN Jr, Dixon CM, et al. Consensus statement on bladder injuries. BJU Int 2004;94:27-32.

42. Delaney C, Kehlet H, Senagore AJ, Bauer AJ, Beart R, et al. Postoperative ileus: profiles, risk factors and definitions. A framework for optimizing surgical outcomes in patients undergoing major abdominal and colorectal surgery. Available from: https://connects.catalyst. harvard.edu/Profiles/display/968180. [Last accessed on 5 Dec 2018]

43. Augestad KM, Delaney CP. Postoperative ileus: impact of pharmacological treatment, laparoscopic surgery and enhanced recovery pathways. World J Gastroenterol 2010;16:2067-74.

44. Boelens PG, Heesakkers FF, Luyer MD, van Barneveld KW, de Hingh IH, et al. Reduction of postoperative ileus by early enteral nutrition in patients undergoing major rectal surgery: prospective, randomized, controlled trial. Ann Surg 2014;259:649-55.

45. Kim CH, Joo JK, Kim HR, Kim YJ. The incidence and risk of early postoperative small bowel obstruction after laparoscopic resection for colorectal cancer. J Laparoendosc Adv Surg Tech A 2014;24:543-9.

46. Mandalà M, Falanga A, Roila F; ESMO Guidelines Working Group. Management of venous thromboembolism (VTE) in cancer patients: ESMO Clinical Practice Guidelines. Ann Oncol 2011;22:vi85-92.

47. Anderin K, Gustafsson UO, Thorell A, Nygren J. The effect of diverting stoma on long-term morbidity and risk for permanent stoma after low anterior resection for rectal cancer. Eur J Surg Oncol 2016;42:788-93.

48. Winter DC, Murphy A, Kell MR, Shields CJ, Redmond HP, et al. Perioperative topical nitrate and sphincter function in patients undergoing transanal stapled anastomosis: a randomized, placebo-controlled, double-blinded trial. Dis Colon Rectum 2004;47:697-703.

49. Mege D, Meurette G, Vitton V, Leroi AM, Bridoux V, et al. Sacral nerve stimulation can alleviate symptoms of bowel dysfunction after colorectal resections. Color Dis 2017;19:756-63.

50. Emmertsen KJ, Laurberg S. Low anterior resection syndrome score: development and validation of a symptom-based scoring system for bowel dysfunction after low anterior resection for rectal cancer. Ann Surg 2012;255:922-8.

51. JJimenez-Gomez LM, Espin-Basany E, Marti-Gallostra M, Sanchez-Garcia JL, Vallribera-Valls F, et al. Low anterior resection syndrome: a survey of the members of the American Society of Colon and Rectal Surgeons (ASCRS), the Spanish Association of Surgeons (AEC), and the Spanish Society of Coloproctology (AECP). Int J Colorectal Dis 2016;31:813-23.

52. Kupsch J, Jackisch T, Matzel KE, Zimmer J, Schreiber A, et al. Outcome of bowel function following anterior resection for rectal cancer-an analysis using the low anterior resection syndrome (LARS) score. Int J Colorectal Dis 2018;33:787-98.

53. de Miguel M, Oteiza F, Ciga MA, Armendáriz P, Marzo J, et al. Sacral nerve stimulation for the treatment of faecal incontinence following low anterior resection for rectal cancer. Colorectal Dis 2011;13:72-7.

54. Samia H, Lawrence J, Nobel T, Stein S, Champagne BJ, et al. Extraction site location and incisional hernias after laparoscopic colorecta surgery: should we be avoiding the midline? Am J Surg 2013;205:264-7.

55. DeSouza A, Domajnko B, Park J, Marecik S, Prasad L, et al. Incisional hernia, midline versus low transverse incision: what is the ideal incision for specimen extraction and hand-assisted laparoscopy? Surg Endosc 2011;25:1031-6.

56. Tan WS, Chew MH, Ho KS, Yatim JB, Lai JS, et al. Short and long-term outcomes of a randomised controlled trial of vertical periumbilical wound versus transverse left iliac fossa wound for specimen retrieval in laparoscopic anterior resections. Surg Endosc 2015;29:2720-7.

57. García-Ureña MÁ, López-Monclús J, Hernando LA, Montes DM, Valle de Lersundi AR, et al. Randomized controlled trial of the use of a large-pore polypropylene mesh to prevent incisional hernia in colorectal surgery. Ann Surg 2015;261:876-81.

58. Watanabe J, Ota M, Kawaguchi D, Shima H, Kaida S, et al. Incidence and risk factors for rectovaginal fistula after low anterior resection for rectal cancer. Int J Colorectal Dis 2015;30:1659-66.

59. Sugarbaker PH. Rectovaginal fistula following low circular stapled anastomosis in women with rectal cancer. J Surg Oncol 
1996;61:155-8.

60. Vogel JD, Johnson EK, Morris AM, Paquette IM, Saclarides TJ, et al. Clinical practice guideline for the management of anorectal abscess, fistula-in-ano, and rectovaginal fistula. Dis Colon Rectum 2016;59:1117-33.

61. Corte H, Maggiori L, Treton X, Lefevre JH, Ferron M, et al. Rectovaginal fistula: what is the optimal strategy? An analysis of 79 patients undergoing 286 procedures. Ann Surg 2015;262:855-60.

62. Duran E, Tanriseven M, Ersoz N, Oztas M, Ozerhan IH, et al. Urinary and sexual dysfunction rates and risk factors following rectal cancer surgery. Int J Colorectal Dis 2015;30:1547-55.

63. Celentano V, Cohen R, Warusavitarne J, Faiz O, Chand M. Sexual dysfunction following rectal cancer surgery. Int J Colorectal Dis 2017;32:1523-30.

64. Shabbir J, Britton DC. Stoma complications: a literature overview. Color Dis 2010;12:958-64.

65. Carne PW, Robertson GM, Frizelle FA. Parastomal hernia. Br J Surg 2003;90:784-93.

66. Hotouras A, Murphy J, Thaha M, Chan CL. The persistent challenge of parastomal herniation: a review of the literature and future developments. Colorectal Dis 2013;15:e202-14.

67. WHO. WHO classification of tumours of the digestive system. Fourth edition. Available from: http://apps.who.int/bookorders/anglais/ detart1.jsp?codlan=1\&codcol=70\&codcch=4003. [Last accessed on 5 Dec 2018]

68. DeAsis FJ, Lapin B, Gitelis ME, Ujiki MB. Current state of laparoscopic parastomal hernia repair: a meta-analysis. World J Gastroenterol 2015;21:8670-7.

69. Al Shakarchi J, Williams JG. Systematic review of open techniques for parastomal hernia repair. Tech Coloproctol 2014;18:427-32.

70. Hansson BM, Morales-Conde S, Mussack T, Valdes J, Muysoms FE, et al. The laparoscopic modified Sugarbaker technique is safe and has a low recurrence rate: a multicenter cohort study. Surg Endosc 2013;27:494-500.

71. Hansson BM, Bleichrodt RP, de Hingh IH. Laparoscopic parastomal hernia repair using a keyhole technique results in a high recurrence rate. Surg Endosc 2009;23:1456-9.

72. Berger D, Bientzle M. Polyvinylidene fluoride: a suitable mesh material for laparoscopic incisional and parastomal hernia repair! A prospective, observational study with 344 patients. Hernia 2009;13:167-72.

73. Serra-Aracil X, Bombardo-Junca J, Moreno-Matias J, Darnell A, Mora-Lopez L, et al. Randomized, controlled, prospective trial of the use of mesh to prevent parastomal hernia. Ann Surg 2009;249:583-7.

74. Cross AJ, Buchwald PL, Frizelle FA, Eglinton TW. Meta-analysis of prophylactic mesh to prevent parastomal hernia. Br J Surg 2017;104:179-86.

75. Burch J. Complications of stomas: their aetiology and management. Br J Community Nurs 2017;22:380-3. 